\title{
Análise dos padrões de difusão espacial dos casos de AIDS por estados brasileiros
}

\author{
Analysis of spatial diffusion patterns for AIDS \\ cases in some Brazilian States
}

Paulo Roberto Telles Pires Dias 1,2

Flavio Fonseca Nobre 2

\footnotetext{
1 Núcleo de Estudose Pesquisas em Atenção ao Uso de Drogas, Universidade do Estado do Rio de Janeiro. Rua Fonseca Teles 121, 4 o andar, Rio de Janeiro, $R J$ 20940-200, Brasil. prtelles@hotmail.com 2 Programa de Engenharia Biomédica, Instituto Alberto Luiz Coimbra de Pós-Graduação e Pesquisa de Engenharia, Universidade Federal do Rio de Janeiro. Centro de Tecnologia, Bloco H, sala H327, Cidade Universitária, C. P. 68510 Rio de Janeiro, $R J$ 21945-970, Brasil.
}

\begin{abstract}
Despite new improvements in AIDS treatment, preventive measures are still essential to control the epidemic. Effective programs almost always depend on correct and efficient allocation of scarce health resources. Detailed information on the epidemic, such as where, when, and how the epidemic will spread are of great value. This study was conducted to obtain a better understanding of the dissemination of AIDS cases in four important Brazilian States. Spatial diffusion patterns were evaluated qualitatively by studying sequential maps and quantitatively by analyzing spatial correlograms. Ten years were analyzed, grouped in three periods (19871989, 1990-1992, and 1993-1996). The diffusion process was studied for both total AIDS cases and male and female cases. Diffusion of AIDS cases presented specific characteristics for each of the four States. Information derived from the study, especially the results of the correlogram analysis, improve our understanding of the epidemic's spatial diffusion in different parts of the country and can also be used to determine parameters for other AIDS epidemiological models.

Key words Spatial Analysis; Spatial Distribution; Acquired Immunodeficiency Syndrome
\end{abstract}

Resumo Ações preventivas ainda são essenciais ao controle da epidemia de AIDS; contudo, programas de prevenção eficazes dependem da distribuição correta e eficiente dos recursos de saúde. Assim, informações acerca de onde, quando, com que intensidade e como se difundirá a epidemia são valiosos. Este estudo visou obter melhor compreensão do processo de difusão espacial dos casos de AIDS em quatro Estados brasileiros. Tais padrões foram avaliados qualitativamente - estudo de mapas seqüenciais - e quantitativamente - análise de correlogramas espaciais - ao longo de dez anos, agrupados em três períodos: 1987-1989, 1990-1992 e 1993-1996. O processo de difusão foi estudado para o total de casos de AIDS e para os do sexo feminino e masculino. De modo geral, houve difusão significativa dos casos de AIDS nos períodos, mas o processo exibiu características específicas a cada Estado. As informações obtidas - em especial, os resultados da análise de correlogramas - permitem entender melhor os padrões de difusão espacial da epidemia em diferentes partes do País e podem ser empregadas para fixar parâmetros a outros modelos epidemiológicos da AIDS.

Palavras-chave Análise Espacial; Distribuição Espacial; Síndrome de Imunodeficiência Adquirida 


\section{Introdução}

Apesar de existir há mais de duas décadas, a epidemia da Acquired Immunological Deficiency Syndrome (AIDS) permanece com questões a serem respondidas. A Organização Mundial da Saúde (OMS) estima que, em todo o mundo, mais de trinta milhões de pessoas estejam contaminadas pelo vírus da imunodeficiência humana (HIV) - vírus da AIDS -, além de o número de pessoas infectadas estar aumentando de forma expressiva - em especial, nos países mais pobres ou em desenvolvimento. O Brasil é um do países com maior número de casos notificados de AIDS no mundo, contando mais de 170 mil casos registrados até agosto de 1999 (MS, 1999) e com estimativa de 399.326 a 603.065 pessoas entre 15 e 49 anos infectadas pelo HIV até 1998 (Szwarcwald \& Castilho, 1999). Os primeiros casos de AIDS identificados em território brasileiro datam do início da década de 80 e ocorreram nas cidades de São Paulo e Rio de Janeiro; desde então, a epidemia apresentou crescimento significativo, atingindo atualmente, embora de forma não homogênea, todas as regiões do País. A maior concentração de casos ocorre na Região Sudeste, nas grandes capitais e em cidades litorâneas (MS, 1999; Szwarcwald et al., 1997).

A epidemia, ao longo dos anos, vem mostrando importantes mudanças em seu perfil. Inicialmente, até meados da década de 80 , a maioria dos casos notificados tinha as relações homossexuais como categoria de exposição e, em menor grau, as transfusões de sangue/hemoderivados, categoria na qual os hemofílicos eram especialmente atingidos. No final da década de 80 , foram progressivamente aumentando os casos decorrentes de outras categorias de exposição, como os casos de AIDS originados pelo uso de drogas injetáveis. Nos últimos anos, passou a ter destaque a transmissão heterossexual. Esta última transição fez-se acompanhar também por significativo incremento dos casos de AIDS entre mulheres, o que pode ser observado na variação da razão de casos segundo sexo ao longo dos anos da epidemia. Esta razão era de 23 homens para 1 mulher em 1984, passando a 3 homens para 1 mulher em 1996/1997 (Castilho et al., 1997; Szwarcwald et al., 1997). Geograficamente, pôde ser evidenciada a "interiorização" dos casos de AIDS no território brasileiro, assim como o aumento da participação dos municípios de menor porte na epidemia - em particular, nos casos decorrentes de transmissão heterossexual (Bastos \& Barcelos, 1995; Szwarcwald et al., 1997).
Apesar dos avanços no tratamento da AIDS, ainda não existem possibilidades de cura ou vacinas para a síndrome; desta forma, as ações de prevenção são essenciais ao controle da epidemia. Estas ações devem ser eficazes e dependem da alocação correta dos quase sempre escassos recursos de saúde. Pesquisas que prestem informações mais detalhadas acerca da epidemia - tais como: onde, quando, e quanto a síndrome irá se difundir - são valiosos.

Este estudo foi desenvolvido com o objetivo de obter maiores informações a respeito da distribuição espacial dos casos de AIDS e de melhor compreender seu processo de difusão. Os padrões de difusão espacial dos casos de AIDS para ambos os sexos em quatro Estados Rio de Janeiro, São Paulo, Santa Catarina e Bahia - foram avaliados qualitativamente, mediante o estudo de mapas seqüenciais, e quantitativamente, através da análise de correlogramas espaciais, para o período de 1987 a 1996.

\section{Os dados}

Foram utilizados os dados relativos aos casos de AIDS em território brasileiro disponibilizados pela Coordenação Nacional de Doenças Sexualmente Transmissíveis e AIDS da Secretaria de Projetos Especiais de Saúde do Ministério da Saúde - atualizados até o início do segundo semestre de 1999. O banco de dados continha informações a respeito de todos os casos de AIDS notificados em território brasileiro desde 1980, ano em que houve o primeiro caso de AIDS no Brasil. Entre as informações disponíveis encontravam-se: município de moradia, data de diagnóstico da AIDS, idade do diagnóstico da AIDS, sexo e categoria de exposição. Como a dinâmica da difusão dos casos de AIDS pediátricos e em adultos segue padrão de difusão distinto, foram considerados neste estudo apenas os casos de AIDS cuja idade de diagnóstico era igual ou superior a 15 anos. A população acima de 14 anos de idade (por sexo) e as coordenadas geográficas da sede municipal dos municípios foram obtidas junto a Fundação Instituto Brasileiro de Geografia e Estatística (IBGE). Como não foram utilizados modelos para correção dos atrasos de notificação - que ocorrem de forma importante com os casos de AIDS (Barbosa \& Struchiner, 1997) -, procurouse minimizar os efeitos desses atrasos pela exclusão dos três últimos anos do banco de dados - 1997, 1998 e 1999 - das análises. 


\section{Métodos}

O estudo dos padrões de difusão espacial foi realizado através de mapas seqüenciais e da análise de correlogramas espaciais. O critério de escolha das regiões estudadas - os Estados de São Paulo, Rio de Janeiro, Santa Catarina e Bahia - é descrito a seguir. São Paulo e Rio de Janeiro foram escolhidos por serem os dois Estados com maior número de casos de AIDS e onde ocorreram os primeiros casos no Brasil, respectivamente, em 1980 e 1982. Santa Catarina apresenta uma das mais elevadas taxas de incidência anual de casos de AIDS ao longo dos últimos anos e possui as maiores taxas de incidência acumulada de casos na Região Sul. Finalmente, a Bahia foi escolhida por ser o Estado com o maior número de casos de AIDS na região nordeste (MS, 1999). Na Tabela 1 podem ser vistos maiores detalhes concernentes à epidemia nos quatro Estados escolhidos.

Na etapa inicial do estudo procurou-se descrever a difusão da AIDS por intermédio de mapas seqüenciais que permitem visualizar graficamente como evoluiu a epidemia em cada um dos Estados considerados. Essa etapa descritiva é importante para o estudo da difusão, pois, como nenhuma outra, permite sua visualização e a análise qualitativa inicial. Deve-se, entretanto, levar em conta suas limitações no que concerne à avaliação de aspectos quantitativos e aos problemas relacionados à escolha dos valores das variáveis a serem agrupadas, os quais serão representados nas legendas (escalas a serem apresentadas nos mapas). Neste estudo, uma análise exploratória inicial indicou que boa opção seria a construção das legendas agrupando-se os valores das taxas dos municípios em quatro classes, utilizando-se os quartis da distribuição destes valores para o último período analisado (1993-1996). Em uma primeira classe estavam os municípios sem casos de AIDS; na segunda classe encontravamse os municípios com valores de taxas até o primeiro quartil; na terceira classe, os municípios com valores de taxas entre o primeiro e terceiro quartis; e na quarta classe, os que possuíam valores acima do terceiro quartil.

Uma vez que o número de casos novos de AIDS por ano (com idade de diagnóstico acima de 14 anos) na maioria do municípios estudados é relativamente pequeno - em geral, da ordem de poucos casos por cem mil habitantes -, a precisão das taxas estimadas torna-se problemática, em particular, para os municípios com populações pequenas (com poucos mil habitantes), onde estas taxas apresentam grande variabilidade. Alguns procedimentos poderiam
Tabela 1

Características dos Estados estudados em relação à epidemia de AIDS.

\begin{tabular}{lccc}
\hline Estado & Casos de AIDS $(\mathbf{n})$ & $\begin{array}{l}\text { Total de casos } \\
\text { do país (\%) }\end{array}$ & $\begin{array}{l}\text { Taxa de incidência } \\
\text { acumulada (casos/ } \\
100 \text { mil habitantes) }\end{array}$ \\
\hline São Paulo & 79.634 & 47 & 247,2 \\
Rio de Janeiro & 25.322 & 15 & 186,8 \\
Santa Catarina & 6.886 & 4 & 158,5 \\
Bahia & 3.872 & 2 & 34,0 \\
\hline
\end{tabular}

ser empregados para contornar tal problema. Um deles seria retirar do estudo os municípios com poucos habitantes, mas esta estratégia levaria a mapas com muitas falhas. O uso de médias ponderadas geograficamente ou transformações que empregam estimadores -como, por exemplo, os Bayesianos ou outros algoritmos de agregação - poderiam melhorar a variabilidade das medidas através de estimativas "suavizadas". Estudos mostram que estas estimativas podem considerar a influência de taxas globais ou de municípios vizinhos para melhorar as estimativas de cada município isolado, o grau de melhoria, em geral, variando diretamente com a variabilidade da taxa do município em questão (Carvalho et al., 1996; Clayton \& Kaldor, 1987; Marshall, 1991).

No presente estudo, para diminuir o problema da variabilidade dos dados - presentes, em especial, nos municípios com menor população - foi utilizada a taxa média da incidência de casos em períodos agrupados. Os períodos agregados foram: 1987 a 1989, 1990 a 1992 e 1993 a 1996. Para o cálculo das taxas, os denominadores (população acima de 14 anos - geral e por sexo) foram estimados por interpolação e extrapolação geométrica dos dados do censo de 1991 e 1996.

Os correlogramas são gráficos que mostram como se comportam as autocorrelações espaciais de uma variável (aqui, taxas médias de incidência) ao longo de uma "distância” geográfica (ou "ordem de vizinhança”). Uma das formas mais simples de definir as vizinhanças - a que foi aqui adotada - é através das distâncias euclidianas. Por exemplo, supondo-se uma distância hipotética de $20 \mathrm{~km}$ para cada ordem de vizinhança, os vizinhos de "primeira ordem" seriam aqueles localizados à distância de até $20 \mathrm{~km}$; os vizinhos de "segunda ordem" seriam aqueles localizados entre 20 e $40 \mathrm{~km}$ e, assim, sucessivamente. No presente estudo, a distância empírica - tamanho do lag - utilizada para 
cada uma das regiões, foi obtida através da soma da distância mínima média entre os municípios, contando com desvio padrão destas distâncias. Outra forma de definição das ordens de vizinhança poderia levar em conta as fronteiras dos municípios. Neste caso, são considerados vizinhos de "primeira ordem" os municípios que compartilham mesma fronteira; "vizinhos de segunda ordem", aqueles que se encontram separados por um vizinho e, assim, sucessivamente.

Lam et al. (1996) sugeriram formas de interpretar correlogramas de acordo com os principais tipos de difusão espacial (hierárquica e por contágio). A difusão por contágio é função direta da distância, operando de forma centrífuga a partir de uma área de origem para fora. Espera-se que o correlograma de determinada região apresente declínio suave e progressivo se a difusão por contágio for predominante. Se o correlograma apresentar simultaneamente valores elevados de autocorrelação espacial positiva, o padrão espacial subjacente pode ser interpretado como sendo fortemente simétrico, sugerindo grandes agrupamentos regionais que servem como centros de difusão.

Qualquer afastamento de um padrão de declínio suave das autocorrelações espaciais no correlograma sugeriria a existência de outros padrões concomitantes de difusão; na maioria dos casos, estes padrões estão relacionados com a hierarquia urbana da região e a fatores tais como a densidade populacional. Por exemplo, se as autocorrelações em um correlograma declinam e depois voltam a subir após alguns lags, formando curva em forma de "V", isto indicaria que regiões mais distantes, ao invés de apresentarem valores progressivamente decrescentes (como na difusão por contágio), apresentariam valores mais elevados (mais correlacionados espacialmente), sugerindo padrão de difusão hierárquico. O padrão hierárquico sugeriria, desta forma, uma possível maior interação populacional entre localidades distantes. Para exemplificar, poderíamos ter municípios com grandes populações e afastados geograficamente, dispondo de eficientes vias de comunicação e transporte. Em outras palavras, vias de transporte eficientes e grande interação sócio-econômica poderiam propiciar maior chance de contato entre populações de localidades mais distantes do que entre áreas geograficamente mais próximas que não dispõem desses atributos.

Na difusão hierárquica, o processo se transmite privilegiando outros "caminhos" que não a simples proximidade geográfica. Na prática, com freqüência, as autocorrelações espaciais nos correlogramas apresentam valores que indicam a existência simultânea de ambas as formas de difusão, tornando, por vezes, a interpretação dos mesmos uma tarefa complexa (Cliff \& Ord, 1981; Lam et al., 1996).

Com relação à escolha do método utilizado para medir as autocorrelações espaciais, foi empregado o índice I de Moran (Cliff \& Ord, 1981; Walter, 1993). Além de ser bastante conhecido, esse índice é utilizado com freqüência em trabalhos de análise da autocorrelação espacial, ademais a vantagem de ser de fácil interpretação, seguindo as noções tradicionais das medidas de autocorrelação não espacial, com valores variando em geral entre -1 e 1 .

A significância estatística dos valores das autocorrelações espaciais alcançadas através do índice I de Moran pode ser determinada segundo as suposições de normalidade (free sampling) e de aleatoriedade (non-free sampling). De acordo com Walter (1993), é possível fazer o cálculo da significância estatística assumindose a suposição de normalidade sempre que o número de pontos na área estudada for superior a 20. Em nosso estudo, como o número de pontos por região é bem superior a 20, esta foi a suposição adotada. Nos correlogramas foram incluídos os intervalos de confiança a 95\% dos valores das autocorrelações espaciais, tendo sido representados por linhas finas sem pontos naquelas figuras.

Apesar de o índice I de Moran ser bem tolerante em relação a desvios da distribuição normal dos dados (Cliff \& Ord, 1981; Walter, 1993), foi realizada uma transformação pela raiz quadrada dos valores dos dados, o que propiciaria distribuição mais simétrica dos mesmos (portanto, mais próxima à distribuição normal) e ajudaria a diminuir uma possível dependência da variância dos dados a sua média (Cressie, 1993).

A fórmula para o cálculo do índice de autocorrelação espacial I de Moran é apresentada a seguir, com os componentes empregados na análise.

$$
I=\frac{n \sum_{i} \sum_{j} w_{(i, j)}\left(x_{(i)}-x\right)\left(x_{(j)}-x\right)}{\sum_{i} \sum_{j} w_{(i, j)} \sum_{i}\left(x_{(i)}-x\right)^{2}}
$$

onde: $n=$ número de municípios em cada Estado $w_{(i, j)}=$ pesos das vizinhanças

$x_{(i)}=$ raiz quadrada da taxa média de incidência para o município $i$ nos períodos estudados $x=$ média dos $x_{(i)}$ para toda a região estudada

Como o número de municípios em três dos Estados estudados - São Paulo, Rio de Janeiro e Santa Catarina - variou durante o período de 
tempo estudado com a criação de vários municípios após 1991, optou-se por adotar, como unidade de referência geográfica, os municípios existentes no ano de 1991. Os municípios criados após este ano tiveram seus casos de AIDS e populações novamente agregados aos municípios que lhes deram origem.

$\mathrm{Na}$ fórmula para o cálculo do índice I de Moran, o valor dos pesos das vizinhanças $\left(w_{i j}\right)-$ que indica o "grau de interação" ou "a relação" entre as vizinhanças - pode ser atribuído conforme vários critérios. Em sua forma mais simples, os pesos podem ser binários, conferindose, por exemplo, o valor 1 às vizinhanças que se deseja incluir no cálculo da autocorrelação espacial e o valor 0 para as demais vizinhanças. Nos correlogramas em que são empregados pesos $\left(w_{i j}\right)$ binários, em geral atribui-se o valor $w_{i j}=1$ às regiões pertencentes à ordem de vizinhança (ou lag) cuja autocorrelação espacial se deseja calcular e o valor $w_{i j}=0$ às regiões pertencentes às demais ordens de vizinhança. Com esta estratégia, é possível estimar as autocorrelações espaciais para diversas ordens de vizinhança, construindo-se o correlograma.

Neste estudo, considerou-se pesos proporcionais ao inverso da distância $\left(w_{i j}=1 / d_{i j}\right)$ para as localidades que pertenciam à ordem de vizinhança (lag) em que se desejava calcular a autocorrelação espacial e pesos $w_{i j}=0$ para as localidades nas demais ordens de vizinhança. Foram calculados, para cada região, os índices de autocorrelação espacial para 8 ordens de vizinhança (lags).

A escolha adequada da distância a partir da qual serão definidas as ordens de vizinhança (ou lags) é importante; se esta distância for grande, perde-se a oportunidade de estudo mais detalhado da região, ao passo que se for pequena, pode-se incluir número restrito de municípios em cada ordem de vizinhança (em especial, no primeiro lag) e corre-se o risco de estudar apenas parcela reduzida da região. Em nosso caso, como já referido, foi utilizado um valor empírico para os lags, igual à distância média mínima entre os municípios da região, acrescidas do valor de desvio padrão destas distâncias.

As análises espaciais foram efetuadas recorrendo-se o pacote estatístico S-Plus versão 4.0 (Mathsoft, 1997), módulo básico e módulo para análises espaciais, além de programas desenvolvidos para a linguagem S-Plus. Os mapas seqüenciais foram desenvolvidos, utilizandose a malha de municípios brasileiros referente ao ano de 1991, fornecida pelo IBGE, e o programa ArcView versão 2.0 (ESRI, 1995).

\section{Resultados}

Os mapas seqüenciais com o número de casos de AIDS por 100 mil habitantes segundo sexo em cada município dos quatro Estados podem ser vistos nas Figuras 1 e 2. É possível observar o processo de difusão ao longo dos três períodos estudados, apesar de ser difícil a caracterização da difusão como sendo processo hierárquico ou por contágio somente através do exame de mapas. O processo parece ter-se iniciado nos municípios em que há grandes metrópoles ou grande população, vizinhos ou não entre si. Para auxiliar a compreensão deste momento inicial da epidemia em cada um dos Estados estudados serão feitas algumas considerações a seguir.

Em São Paulo, os seis municípios com cinco ou mais casos de AIDS em 1985 - São Paulo, Campinas, Santos, Santo André, São Bernardo e São José dos Campos - encontram-se entre os que possuem as maiores populações do Estado, porém apenas São Bernardo e Santo André são vizinhos contíguos de São Paulo, onde ocorreram os primeiros casos de AIDS. No Rio de Janeiro, os sete municípios com mais de cinco casos de AIDS em 1986 - Rio de Janeiro, Nova Iguaçú, Niterói, Duque de Caxias, São Gonçalo, São João de Meriti e Nilópolis - são todos, com exceção de São Gonçalo, vizinhos contíguos do Rio de Janeiro, local onde teve início a epidemia no Estado. Em Santa Catarina, os oito municípios com mais de cinco casos de AIDS em 1989 - Florianópolis, Itajaí, Balneário de Camboriú, Blumenau, Joinvile, São José, Brusque e Tubarão -, com exceção de São José e Florianópolis, não são vizinhos contíguos entre si. Na Bahia, em 1988, os cinco municípios com mais de cinco casos de AIDS Salvador, Itabuna, Feira de Santana e Juazeiro -, todos entre os mais populosos do Estado, não são vizinhos contíguos. Como podemos notar pelo acima descrito, a difusão hierárquica dos casos de AIDS parece estar presente na maioria dos Estados estudados.

A observação dos correlogramas espaciais (Figuras 3 e 4) permite análise mais aprofundada dos processos de difusão em andamento. Em cada uma das figuras foram apresentados os correlogramas espaciais de dois Estados. Para cada um deles foram realizados nove correlogramas e dois histogramas. A primeira "linha" da figura corresponde aos correlogramas dos três períodos estudados - 1987-1989, 19901992 e 1993-1996 -, considerando o total de casos de AIDS notificados durante estes períodos. Os correlogramas da segunda "linha" examina os mesmos períodos para os casos do se- 
Mapas seqüenciais das taxas médias de incidência de casos de AIDS (com idade de diagnóstico acima de 14 anos) nos períodos 1987 a 1989, 1990 a 1992 e 1993 1996, para o Estado de São Paulo.

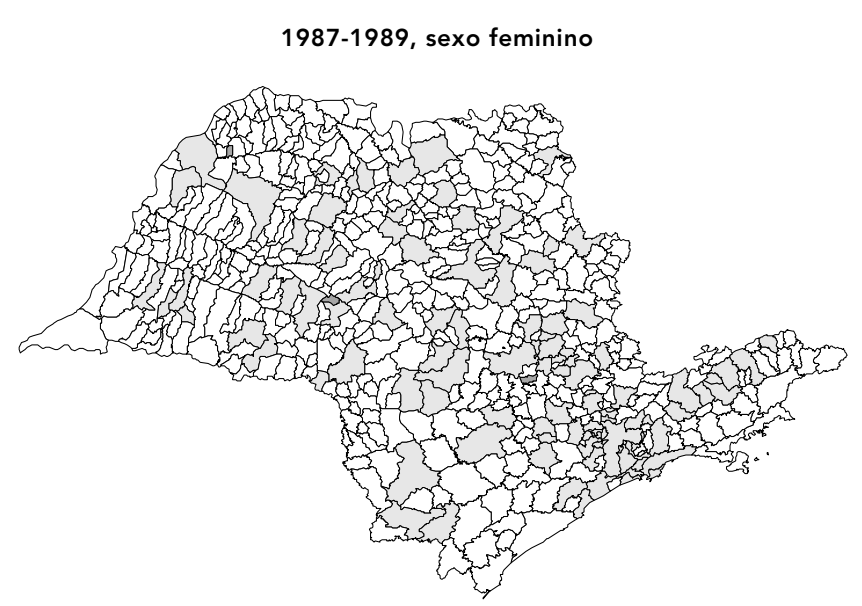

1990-1992, sexo feminino

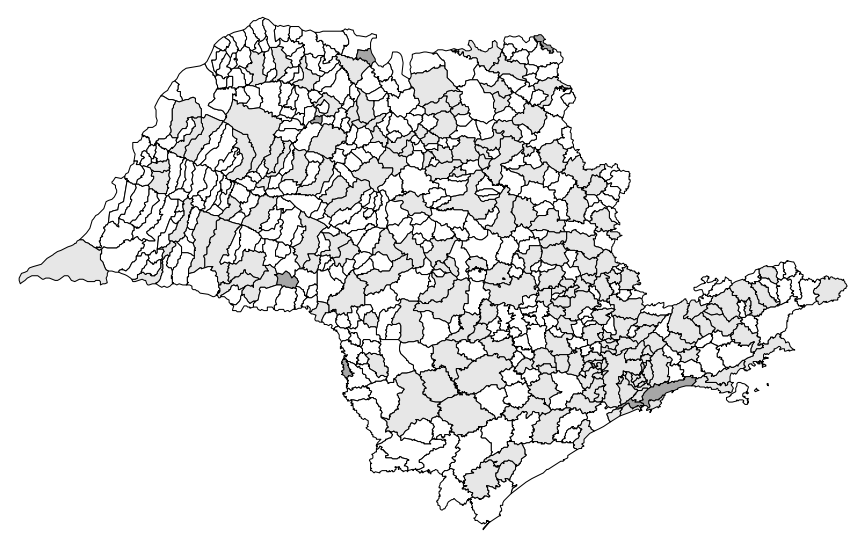

1993-1996, sexo feminino

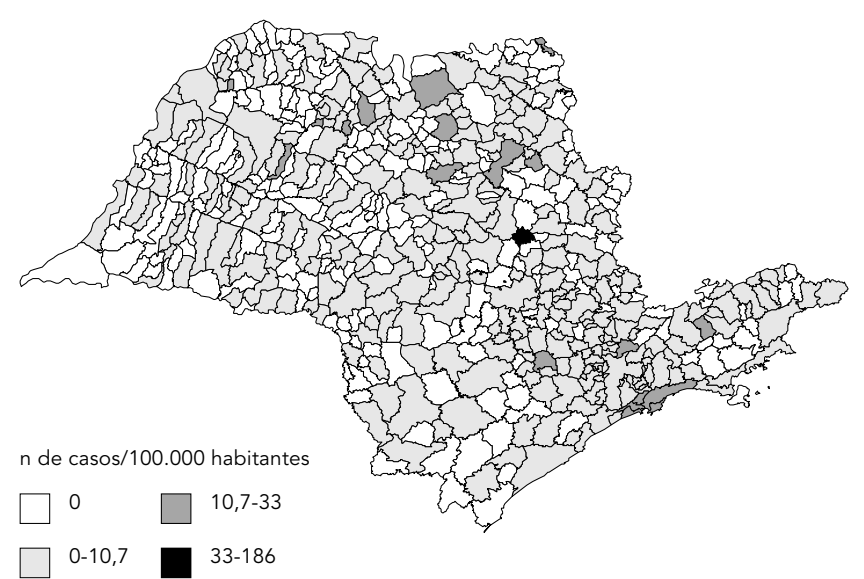

Figura $1 b$

1987-1989, sexo masculino

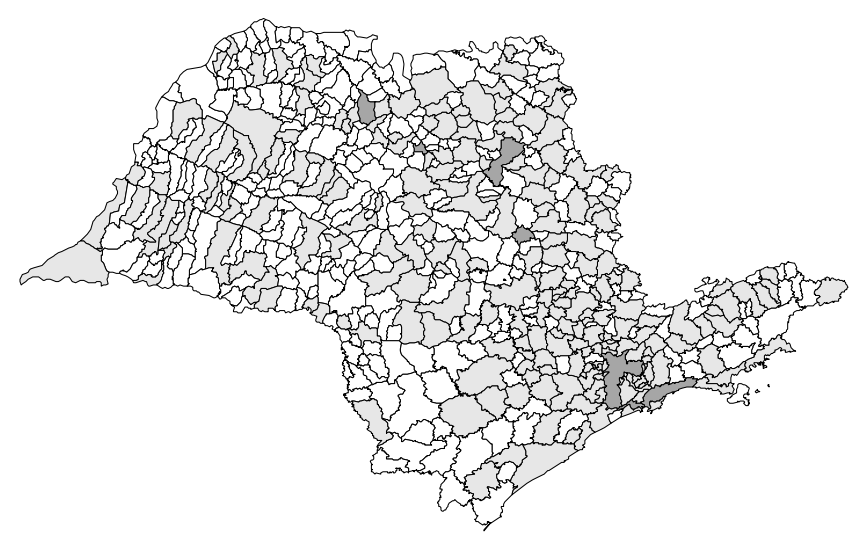

1990-1992, sexo masculino

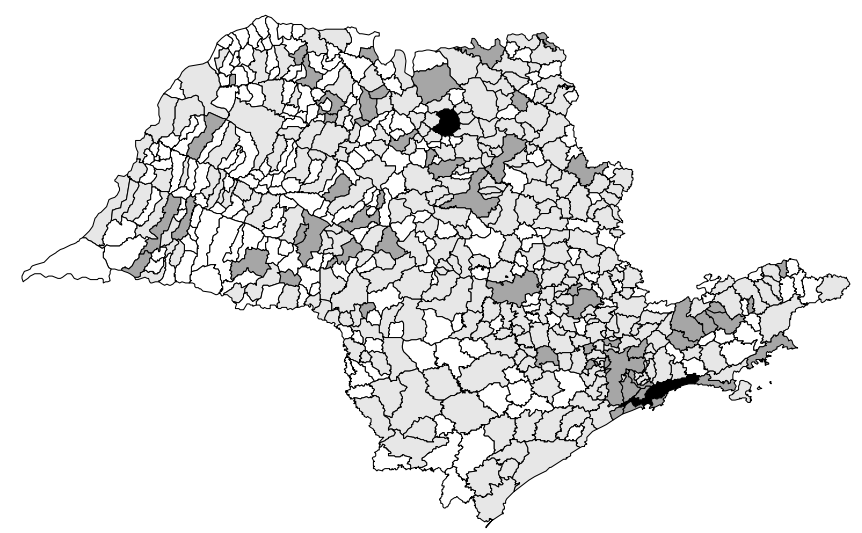

1993-1996, sexo masculino

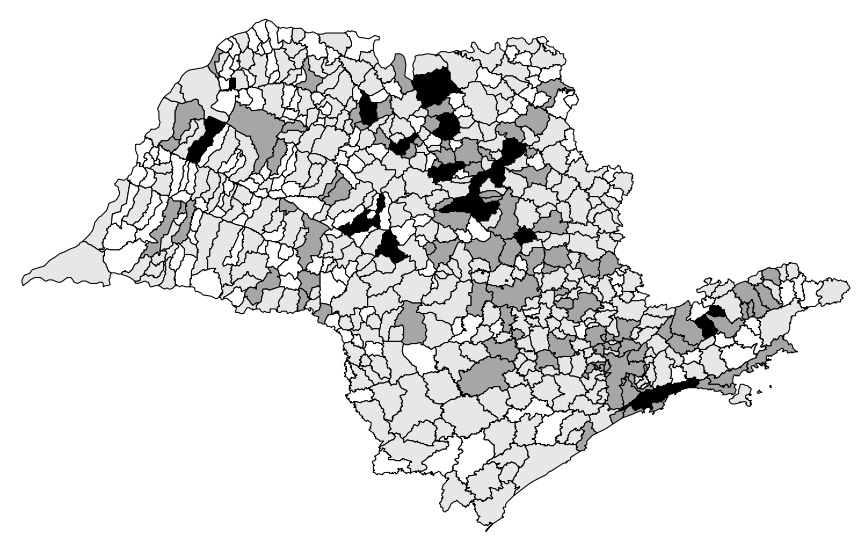


Mapas seqüenciais das taxas médias de incidência de casos de AIDS (com idade de diagnóstico acima de 14 anos) nos períodos 1987 a 1989, 1990 a 1992 e 1993 1996, para o Estado do Rio de Janeiro.

1987-1989, sexo feminino

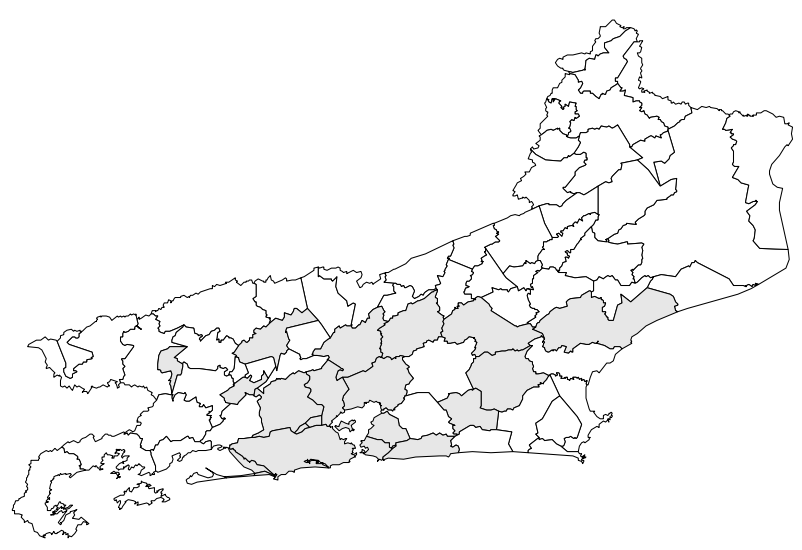

1990-1992, sexo feminino

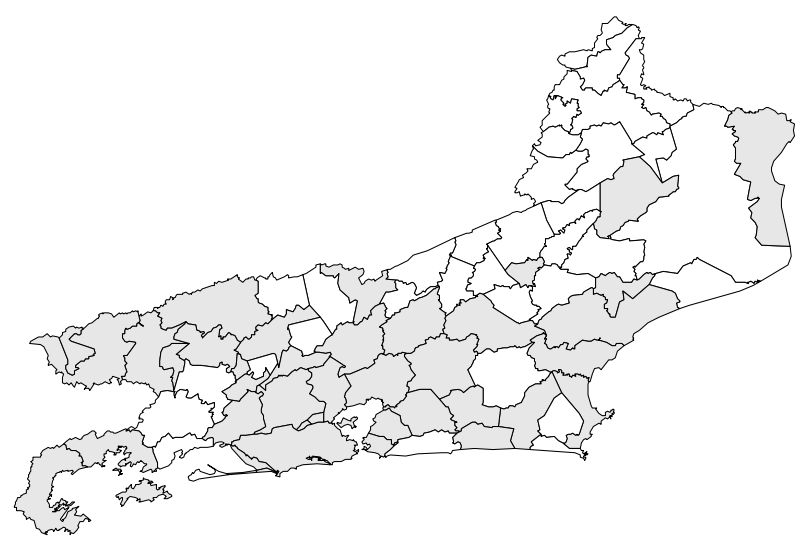

1993-1996, sexo feminino

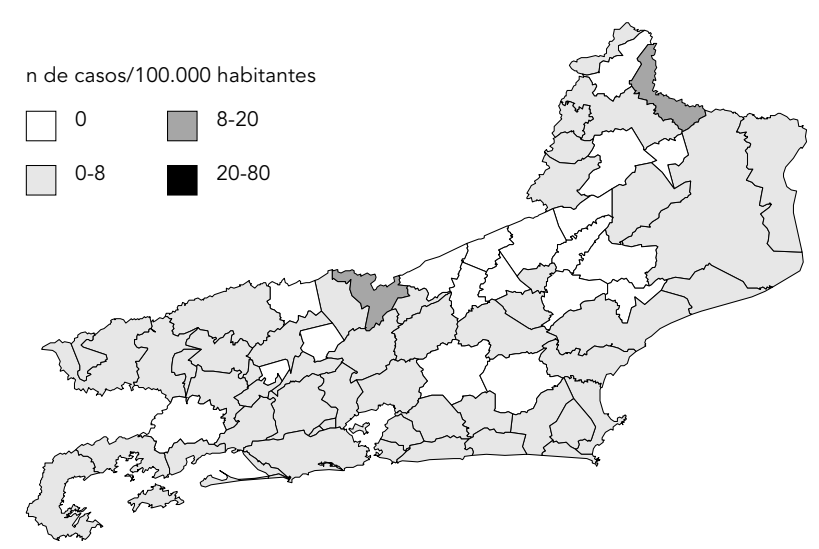

Figura 1d

1987-1989, sexo masculino

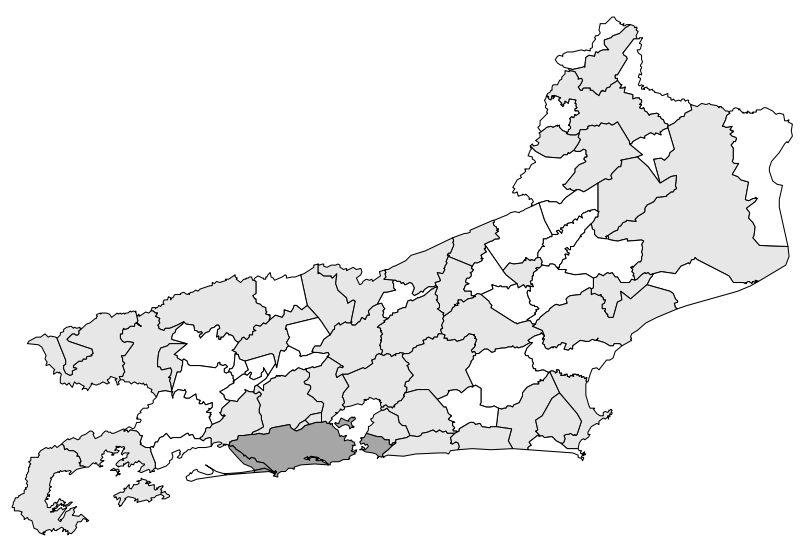

1990-1992, sexo masculino

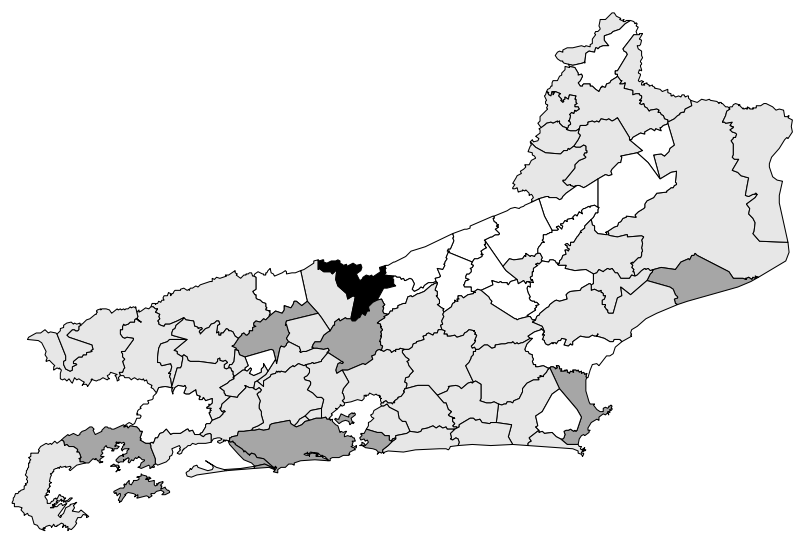

1993-1996, sexo masculino

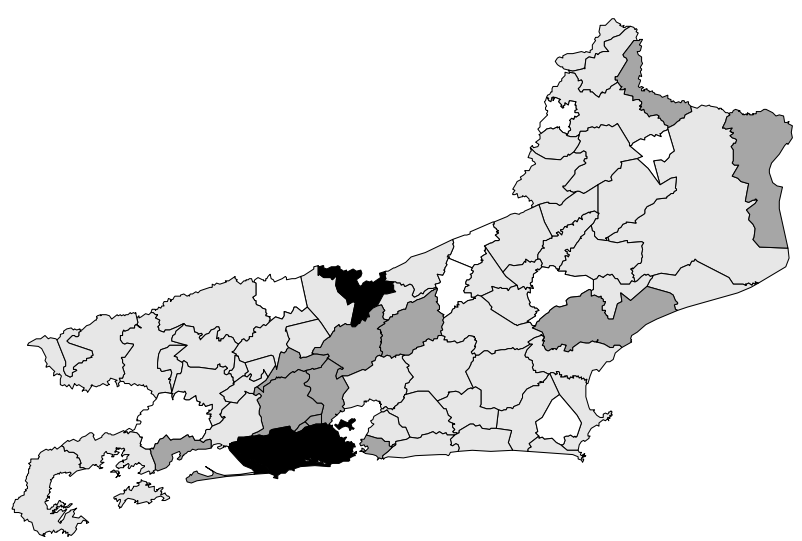


1987-1989, sexo feminino

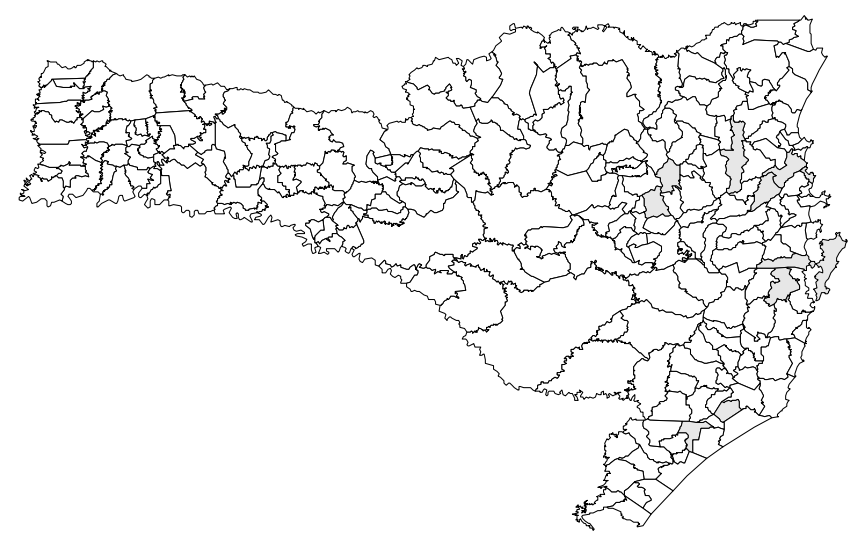

1990-1992, sexo feminino

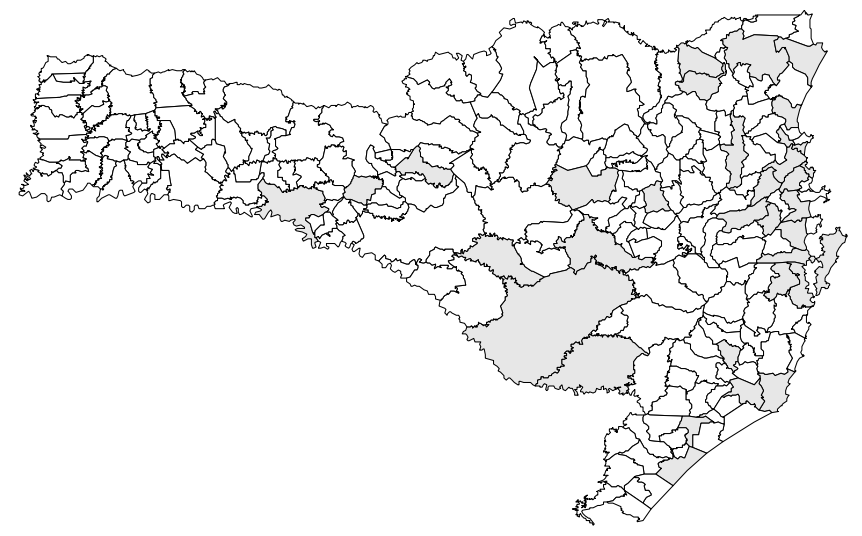

1993-1996, sexo feminino

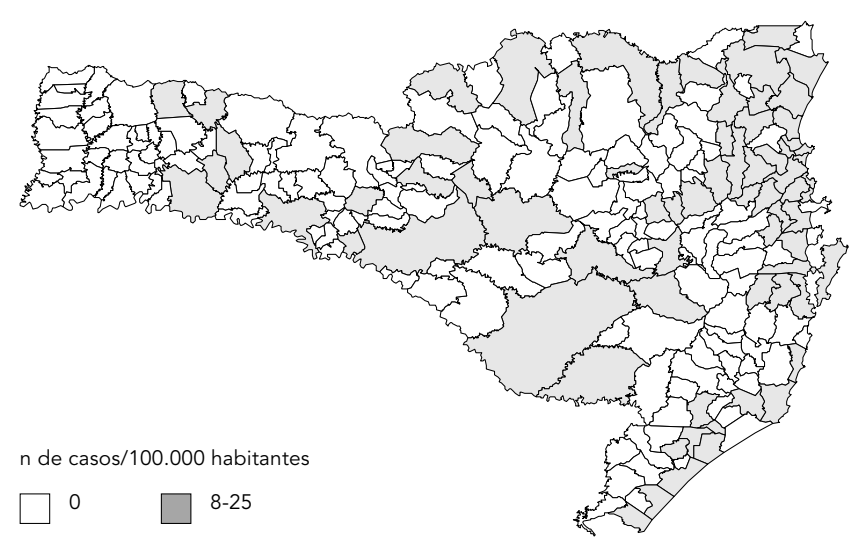

1987-1989, sexo masculino

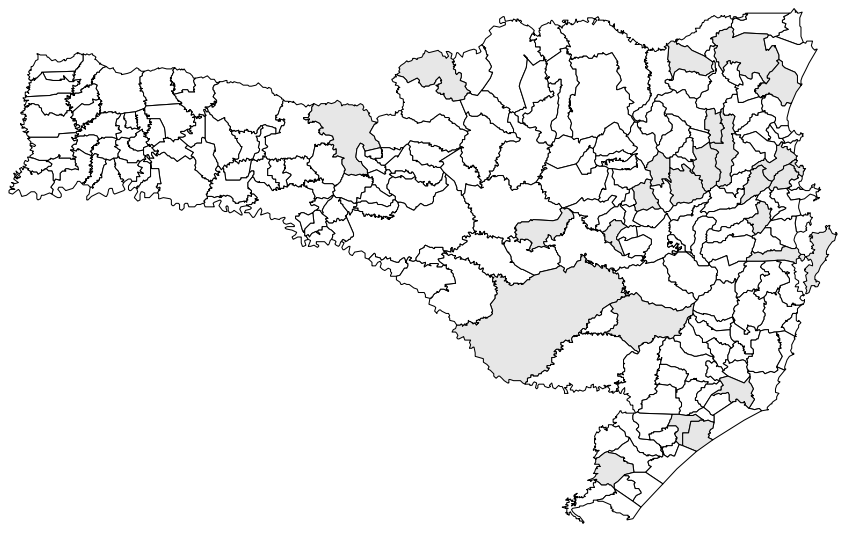

1990-1992, sexo masculino

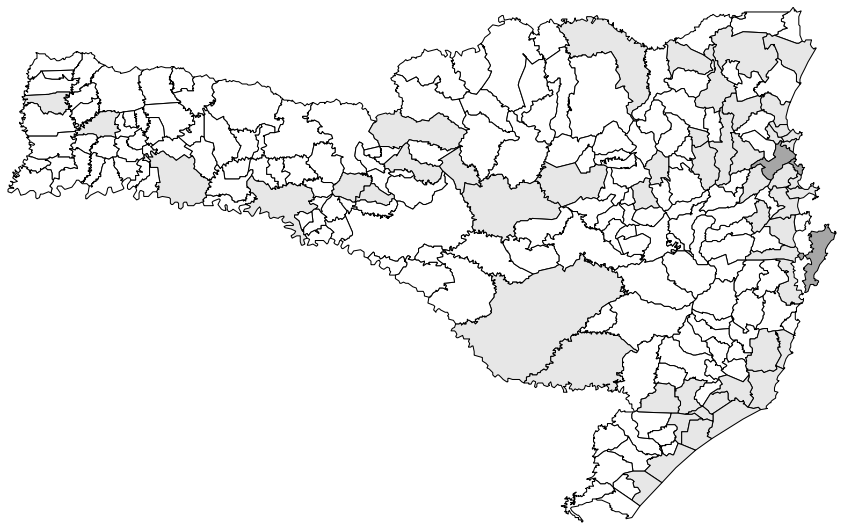

1993-1996, sexo masculino

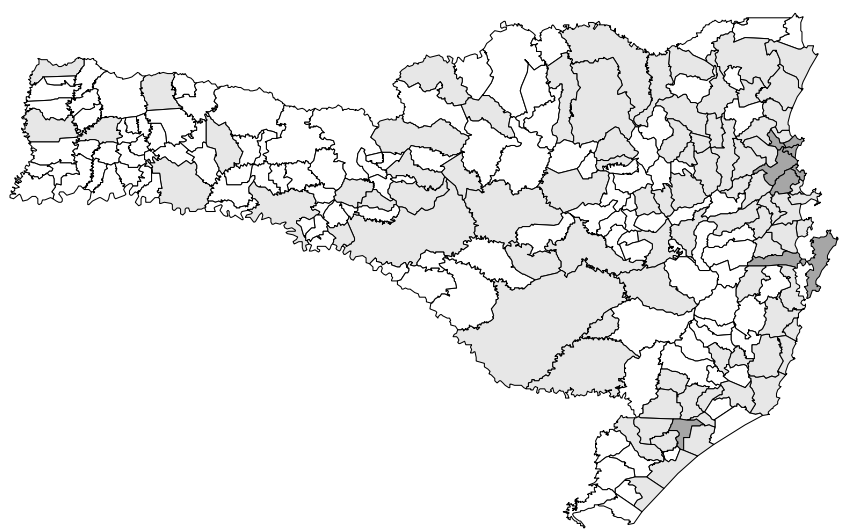


Figura 2

Mapas seqüenciais das taxas médias de incidência de casos de AIDS (com idade de diagnóstico acima de 14 anos) nos períodos 1987 a 1989, 1990 a 1992 e 1993 1996, para o Estado da Bahia.

1987-1989, sexo feminino

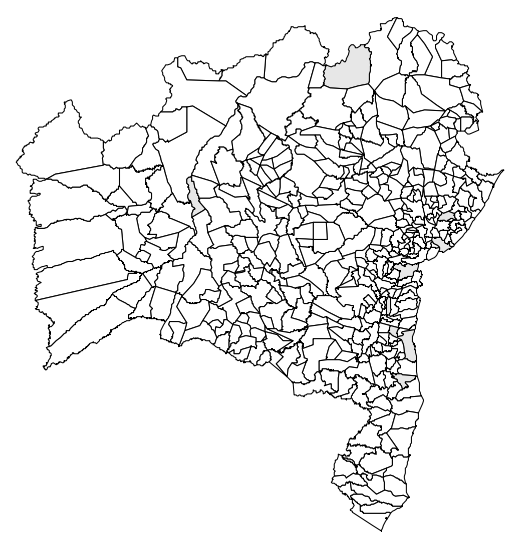

1990-1992, sexo feminino

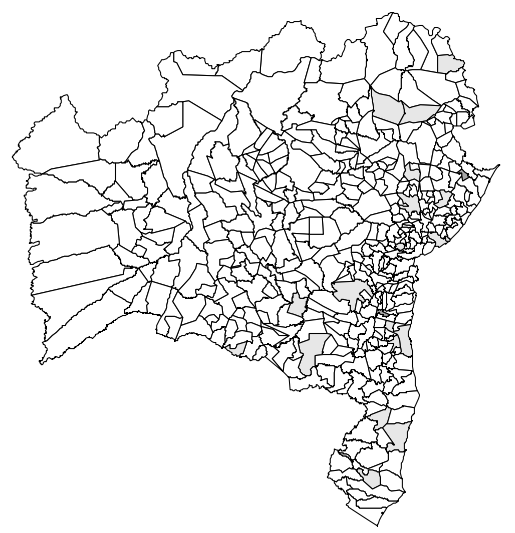

1993-1996, sexo feminino

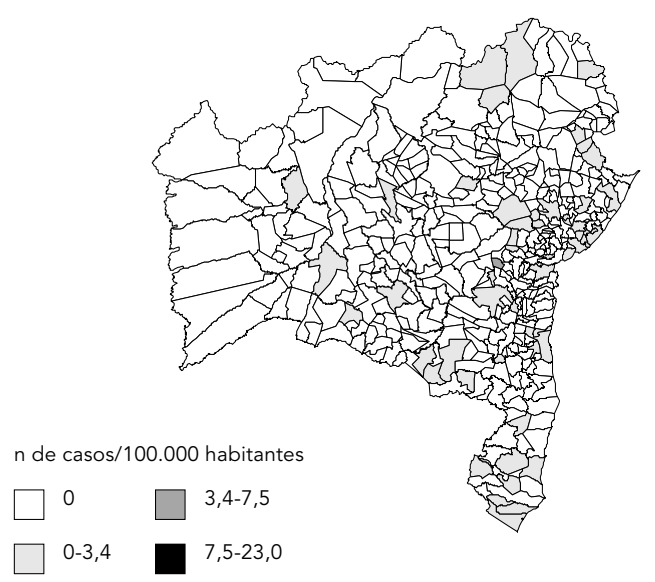

1987-1989, sexo masculino

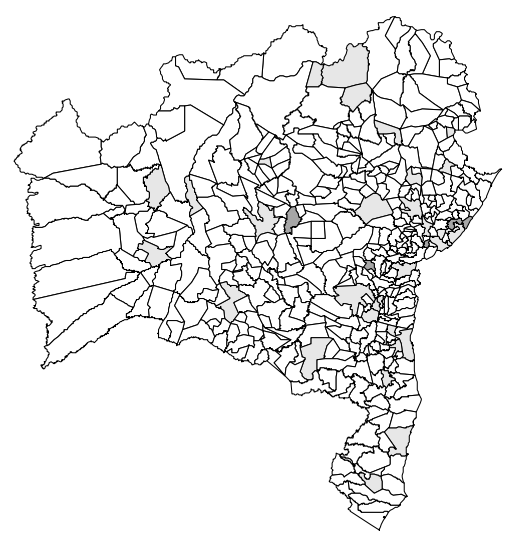

1990-1992, sexo masculino

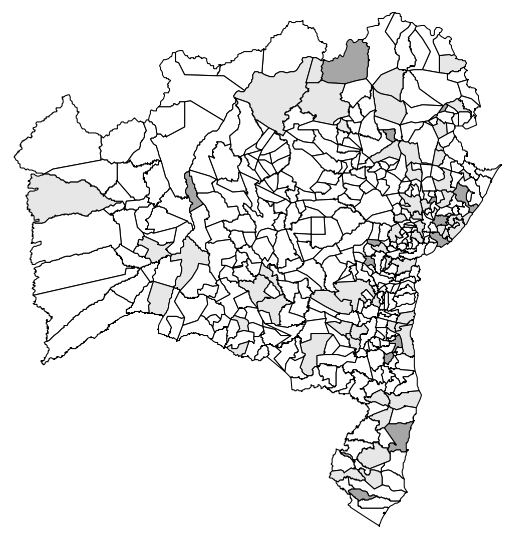

1993-1996, sexo masculino

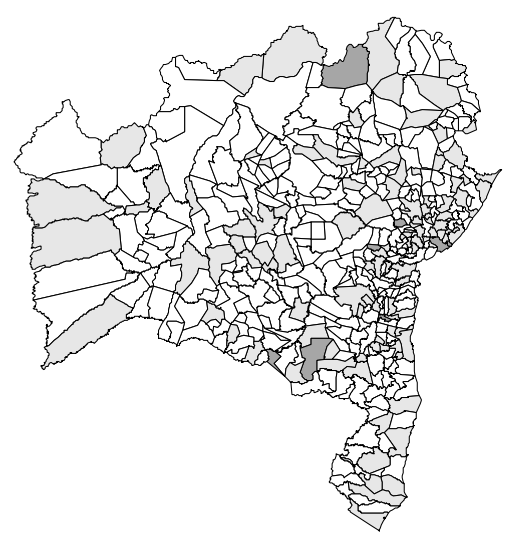


Correlogramas espaciais e histogramas do número de casos de AIDS com idade de diagnóstico acima de 14 anos (total e por sexo), para o Estado de São Paulo, para os períodos de 1987-1989, 1990-1992 e 1993-1996.
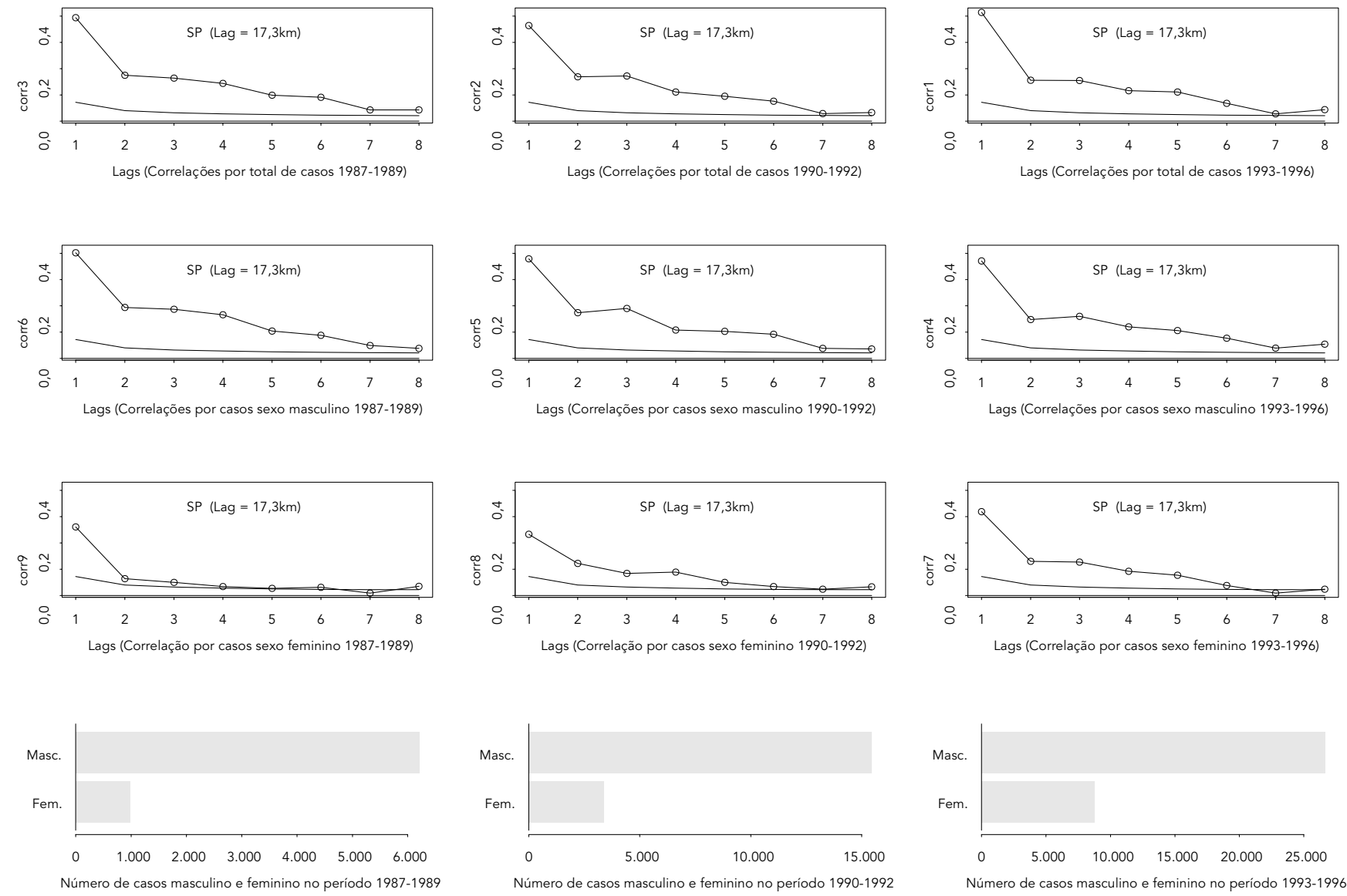

corr = correlograma; SP = São Paulo.

xo masculino e a terceira "linha" para os casos do sexo feminino. Por fim, na quarta "linha" são apresentados histogramas com o número de casos entre homens (coluna superior do histograma) e mulheres (coluna inferior) para cada um dos períodos. As "linhas" 5, 6, 7 e 8 representam, de forma semelhante às acima descritas, as informações relativas ao segundo Estado representado na figura.

De maneira geral, os correlogramas mostram as peculiaridades do processo de difusão para cada um dos Estados. Complementam-se as informações dos correlogramas com o número de novos casos de AIDS por período e sexo (apresentados nos histogramas das Figuras 3 e 4) e com a evolução anual do número de novos casos de AIDS por 100 mil habitantes exibida na Figura 5.
Os correlogramas para o Estado de São Paulo (correlogramas da metade superior da Figura 3) apresentam-se bastante semelhantes ao longo dos três períodos estudados. As autocorrelações espaciais mostram-se quase sempre positivas e estatisticamente significativas em todos os lags espaciais. Um padrão declinante progressivo, mais ou menos regular, das autocorrelações espaciais desde as primeiras até as últimas ordens de vizinhança estudadas sugere que uma difusão por contágio foi o processo predominante neste Estado nos períodos considerados. Os elevados índices de autocorrelação também indicam a presença de padrão simétrico de difusão, em que municípios com elevada concentração de casos estariam funcionando como centros difusores da epidemia para os municípios adjacentes. 
Correlogramas espaciais e histogramas do número de casos de AIDS com idade de diagnóstico acima de 14 anos (total e por sexo), para o Estado do Rio de Janeiro, para os períodos de 1987-1989, 1990-1992 e 1993-1996.
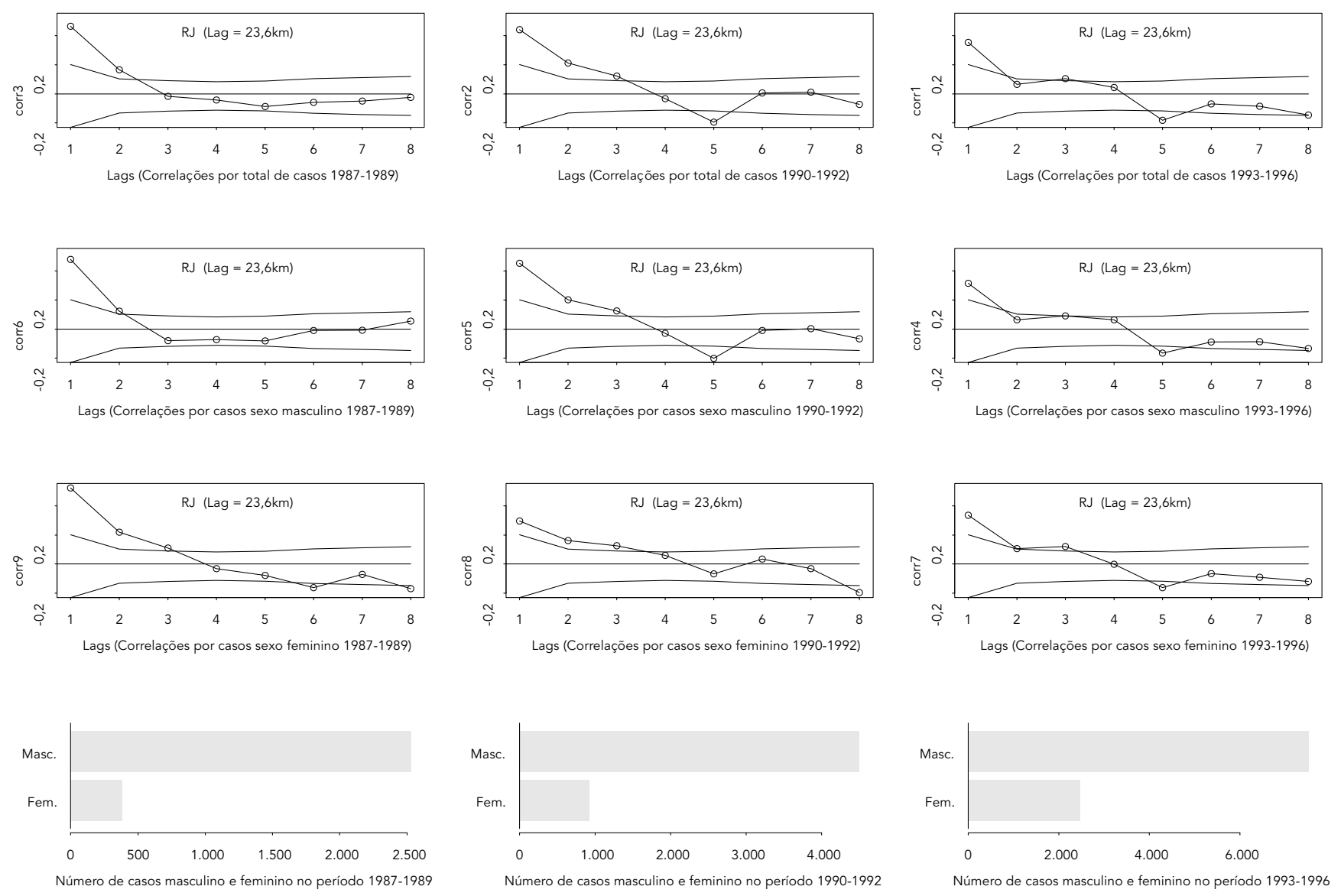

corr = correlograma; RJ = Rio de Janeiro

Os correlogramas espaciais do Rio de Janeiro (na metade inferior da Figura 3) apresentam-se, em geral, menos regulares que os de São Paulo. Nos correlogramas dos dois últimos períodos, as autocorrelações espaciais positivas e estatisticamente significativas dos primeiros lags vão declinando até o $\operatorname{lag} 5$, assumindo valores negativos estatisticamente significativos. Após o $\operatorname{lag} 5$, as autocorrelações espaciais voltam a aumentar, evidenciando discreto crescimento e sugerindo um possível componente hierárquico na difusão.

Em Santa Catarina (Figura 2), pode-se notar diferença entre os padrões de autocorrelação presentes nos correlogramas espaciais do primeiro período em relação aos dois últimos. No primeiro período, as autocorrelações espaciais assumem padrão irregular, com autocor- relações espaciais positivas e estatisticamente significativas afastadas entre si por alguns lags, sugerindo, de certa forma, a presença de um componente hierárquico no processo de difusão (padrão em "V" nos lags 1 a 4). O padrão das autocorrelações nos correlogramas espaciais dos dois últimos períodos assemelhamse; nos primeiros lags, mostram-se positivas, estatisticamente significativas e declinantes, sugerindo a presença de difusão por contágio. No período final, há intensificação dos valores das autocorrelações espaciais em relação ao período anterior. Cabe ressaltar também que nos correlogramas deste último período foram encontrados os maiores valores para as autocorrelações espaciais dentre todos os Estados estudados, chegando a valores superiores a 0,8 no primeiro lag, reforçando a idéia de haver 
Correlogramas espaciais e histogramas do número de casos de AIDS com idade de diagnóstico acima de 14 anos (total e por sexo), para o Estado de Santa Catarina, para os períodos de 1987-1989, 1990-1992 e $1993-1996$.
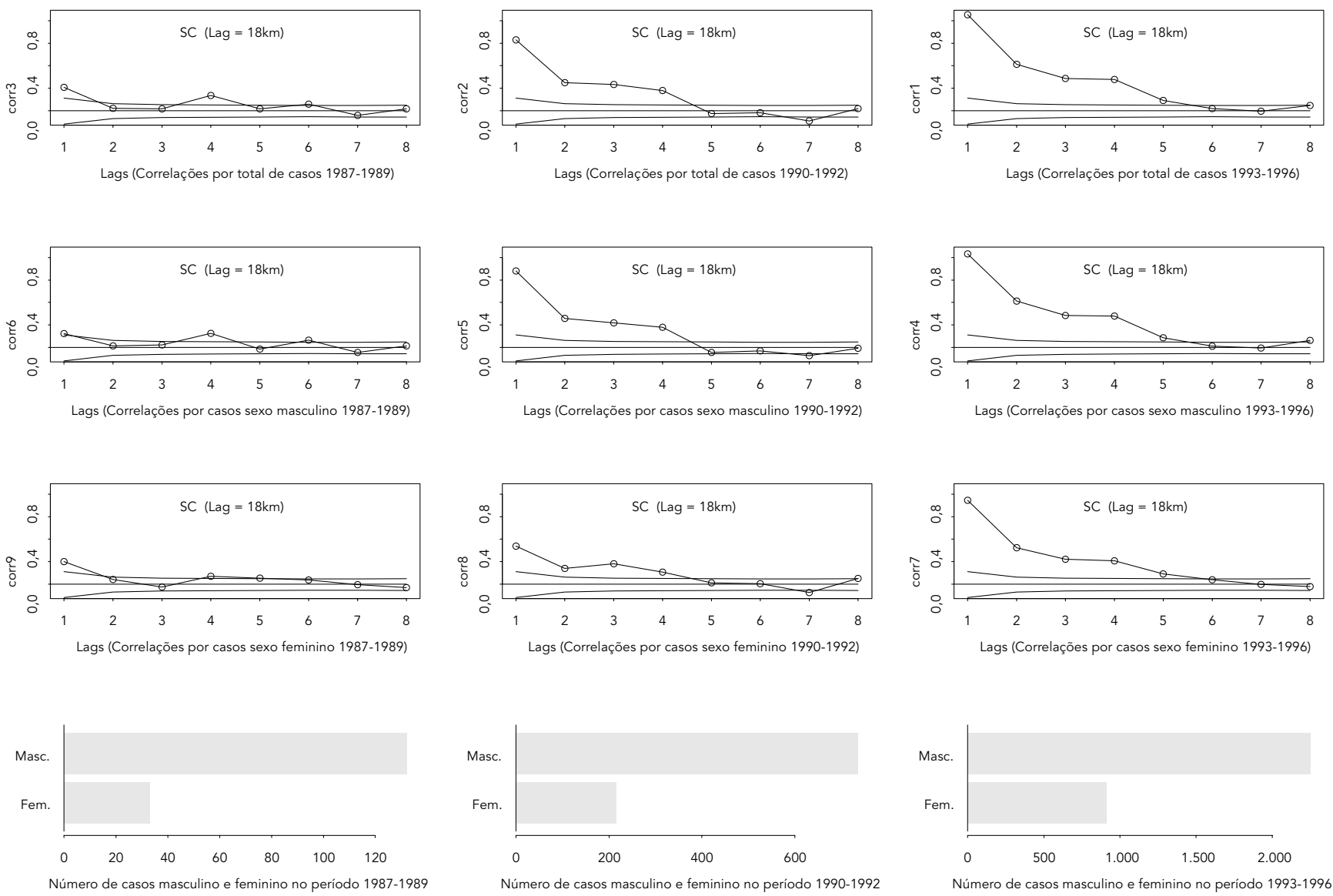

corr = correlograma; $\mathrm{SC}=$ Santa Catarina

municípios com altas taxas que funcionam como centros difusores da epidemia.

Os correlogramas para o Estado da Bahia foram os que expuseram os padrões mais irregulares tanto ao longo dos períodos estudados como entre os sexos (Figura 2). Nos dois primeiros períodos, os correlogramas exibem pequenos valores de autocorrelações não estatisticamente significativos na maioria das vezes. No período inicial (87-89), pode-se questionar a presença de um possível padrão em "V" para os lags 1 a 7 . Nos correlogramas do último período, as autocorrelações espaciais começam a expor padrão mais bem definido. No sexo feminino este padrão é decrescente e progressivo, sugerindo a caracterização de difusão por contágio. As autocorrelações espaciais no correlograma do sexo masculino deste período, apesar do padrão menos regular, apresentam a mesma tendência.

\section{Discussão}

Este estudo demonstra o uso de correlogramas para descrever quantitativamente os padrões espaciais de difusão dos casos de AIDS para quatro Estados brasileiros durante o período de 1987-1996. A mesma técnica poderia ser utilizada para outras regiões ou países, ou mesmo para a análises dos padrões de difusão dos casos de AIDS separados em função de categorias de transmissão com o intuito de realizar estudos e comparações adicionais.

Nos períodos estudados houve variações regionais dos padrões de difusão espacial, ten- 
Correlogramas espaciais e histogramas do número de casos de AIDS com idade de diagnóstico acima de 14 anos (total e por sexo), para o Estado da Bahia, para os períodos de 1987-1989, 1990-1992 e 1993-1996.
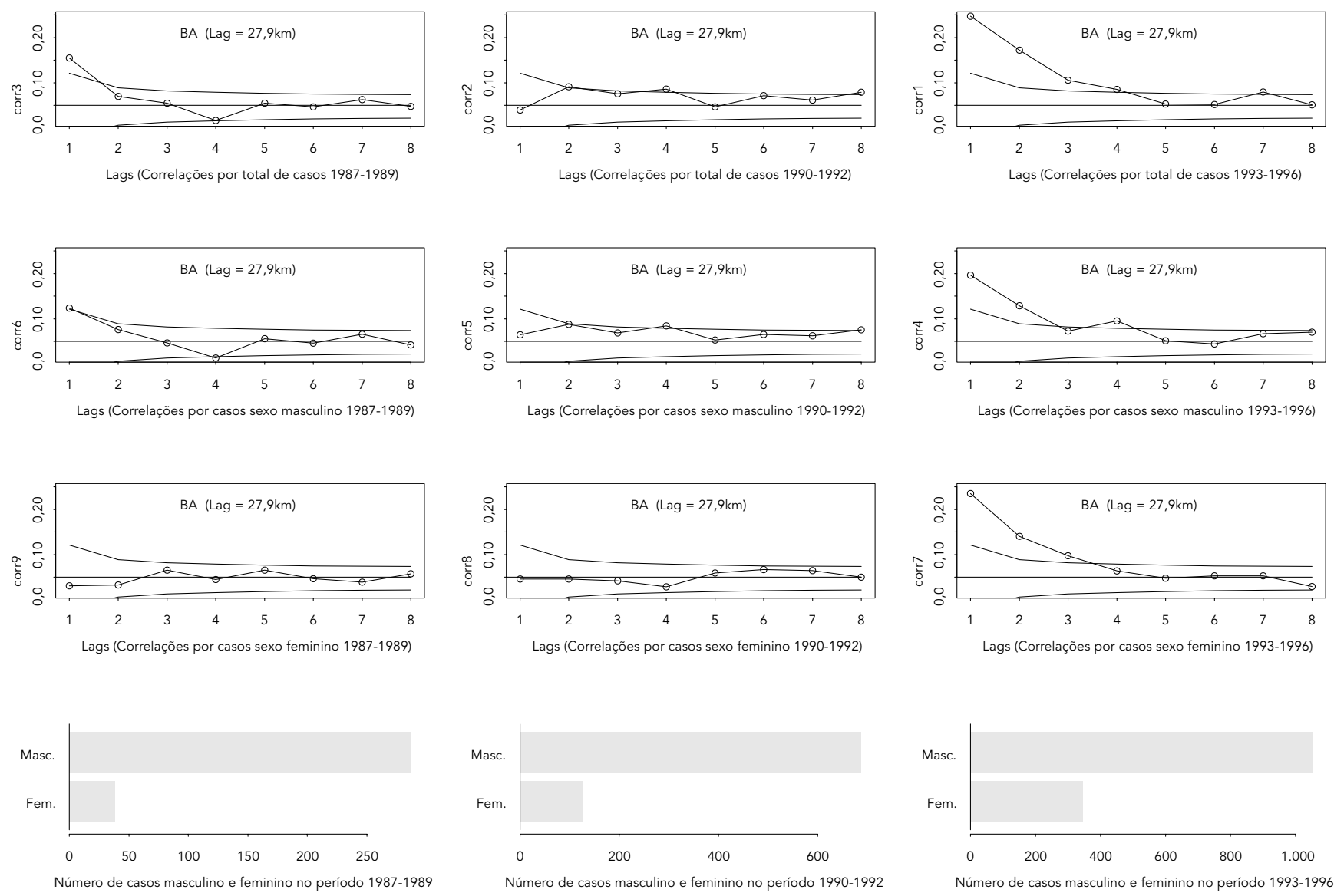

corr = correlograma; $\mathrm{BA}=$ Bahia .

do-se observado, especialmente para Santa Catarina e Bahia, tendência semelhante à já registrada em outros estudos de difusão dos casos de AIDS (Gardner et al., 1989; Lam et al., 1996; Loytonen \& Arbona, 1996), em que haveria transição de um padrão de difusão hierárquico, predominante nas fases iniciais da epidemia, para difusão por contágio, quando a epidemia já está há algum tempo estabelecida na região. Loytonen (1991), apesar de ter estudado a difusão espacial dos portadores de HIV - o que representaria circunstância diferente tanto em termos cronológicos como de critérios de definição (em relação aos casos de AIDS) - encontrou transição semelhante dos padrões de difusão espacial em seu estudo realizado na Finlândia.

Um dos motivos para esta tendência - transição hierárquico-contágio - ter sido observa- da mais claramente para Santa Catarina e Bahia, pode estar relacionada com a escolha do período estudado nos correlogramas, uma vez que a epidemia instalou-se mais tardiamente nesses Estados. O período de difusão hierárquica para São Paulo e Rio de Janeiro poderia ter ocorrido antes da época estudada, não tendo sido possível, portanto, a sua detecção. Para Santa Catarina e Bahia, como descrito anteriormente, os primeiros municípios com mais de cinco casos de AIDS foram detectados em 1989 e 1988, respectivamente, sendo que estes municípios, em sua grande maioria, não eram vizinhos, reforçando a hipótese de difusão hierárquica inicial.

No caso do Estado de São Paulo, os correlogramas espaciais mostraram padrão semelhante entre si - sugerindo difusão predomi- 
Figura 5

Taxas de incidência anuais de casos de AIDS.

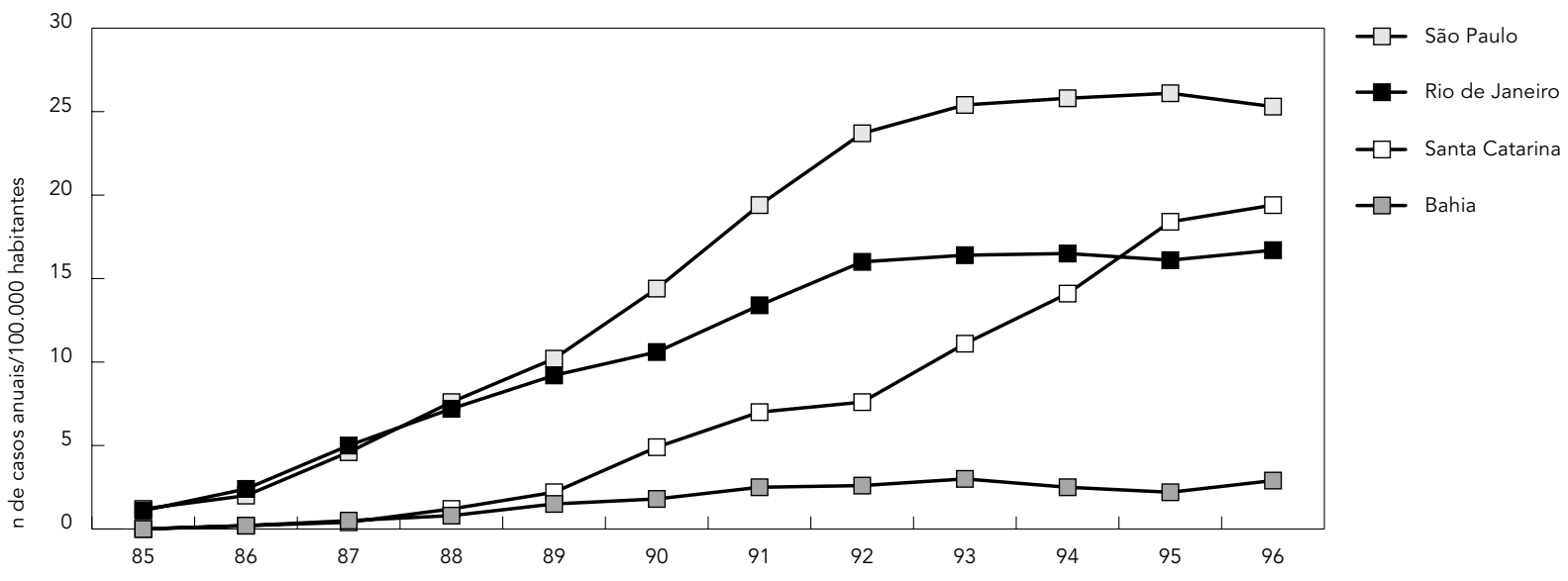

nante por contágio - durante todos os períodos estudados, o que não impede que uma possível análise de períodos anteriores da epidemia para este Estado possa evidenciar padrões diferentes de difusão. São Paulo foi o Estado em que a epidemia se iniciou mais precocemente, contribuindo atualmente com cerca de $50 \%$ dos casos de AIDS de todo o País. Já em 1985 época não incluída no presente estudo -, foram observados seis municípios com mais de cinco casos de AIDS neste Estado, os quais eram, em sua maioria, municípios não vizinhos entre si (MS, 1999).

Para o Rio de Janeiro evidenciou-se padrão de difusão um pouco diferente dos demais Estados, em particular, no que concerne à transição entre padrão de difusão hierárquico para um de contágio. As autocorrelações positivas e estatisticamente significativas são mais freqüentes nos dois primeiros períodos estudados em relação ao último período, assim como são menores os valores das autocorrelações espaciais nos dois primeiros lags para o último período. Um possível componente hierárquico (com o vértice do "V" no lag 5) mantém-se presente em quase todos os correlogramas até o último período estudado. Cabe ressaltar que, ao contrário dos outros Estados, os primeiros municípios com mais de cinco casos de AIDS no Rio de Janeiro foram, em sua maioria, vizinhos contíguos, reforçando a hipótese de que, desde o início da epidemia, pode ter havido um componente importante de difusão por contágio, o qual parece não se ter intensificado ao longo do tempo.

Apesar do número de casos de AIDS em todos os Estados estudados ser bem mais elevado para o sexo masculino do que para o feminino, os correlogramas, na maioria dos casos, mostrou padrão semelhante de difusão espacial para ambos os sexos - em especial, nos dois últimos períodos estudados. Isto poderia sugerir que a difusão espacial dos casos de AIDS, ao menos para os últimos períodos estudados, tem-se dado de forma semelhante para ambos os sexos.

Como vimos anteriormente, a definição dos pesos das vizinhanças e a escolha das suposições para os testes de significância estatística - normalidade ou aleatoriedade - poderiam afetar os resultados dos correlogramas, bem como suas interpretações subseqüentes. Com o intuito de avaliar o efeito de possíveis modificações dessas condições nos resultados encontrados em nosso estudo, foram gerados correlogramas que consideravam diferentes definições de pesos para as vizinhanças e suposições para o teste de significância estatística dos resultados. Apesar de não apresentados neste estudo, verificou-se que: (a) o emprego de diferentes definições de pesos das vizinhanças, tais como: pesos binários, e pesos ponderados não só pela distância mas pela "direcionalidade" da difusão - supondo-se que a difusão se daria de forma diferente entre dois municípios de populações diferentes - não acarre- 
taram diferenças importantes nos resultados; e que (b) testes de significância estatística baseados em suposição de aleatoriedade da amostra (non-free sampling) também produziram resultados semelhantes aos fundados na suposição de normalidade da amostra.

Apesar de suas limitações, as informações decorrentes da análise de correlogramas permitem maior compreensão dos padrões de difusão espaço-temporal da epidemia, podendo

\section{Agradecimentos}

Apoio Fundação de Amparo a Pesquisa do Rio de Janeiro, e Projeto Pronex, Ministério de Ciência e Tecnologia/Conselho Nacional de Desenvolvimento Científico e Tecnológico/Financiadora de Estudos e Projetos.

\section{Referências}

BARBOSA, M. T. S. \& STRUCHINER, C. J., 1997. Estimativas do número de casos de AIDS: Comparação de métodos que corrigem o atraso de notificação. In: Epidemia de AIDS no Brasil: Situações e Tendências (P. N. Chequer \& M. G. Medeiros, org.), pp. 15-26, Brasília: Coordenação Nacional de DST e AIDS, Secretaria de Projetos Especiais de Saúde, Ministério da Saúde.

BASTOS, F. I. \& BARCELOS, C., 1995. A geografia social da AIDS no Brasil. Revista de Saúde Pública, 29:52-62.

CARVALHO, M. S.; CRUZ, O. G. \& NOBRE, F. F., 1996. Spatial partitioning using multivariate cluster analysis and a contiguity algorithm. Statistics in Medicine, 15:1885-1894.

CASTILHO, E. A. \& CHEQUER, P., 1997. A epidemia da AIDS no Brasil. In: Epidemia de AIDS no Brasil: Situações e Tendências (P. N. Chequer \& M. G. Medeiros, org.), pp. 9-12, Brasília: Coordenação Nacional de DST e AIDS, Secretaria de Projetos Especiais de Saúde, Ministério da Saúde.

CLAYTON, D. \& KALDOR, J., 1987. Empirical Bayes estimates of age-standardized relative risks for use in disease mapping. Biometrics, 43:671-681.

CLIFF, A. D. \& ORD, J. K., 1981. Spatial Processes, Models and Applications. London: Pion.

CRESSIE, N., 1993. Statistics for Spatial Data. New York: Willey.

ESRI (Environmental Systems Research Institute Inc.), 1995. ArcView, Version 2.0. Redlands: ESRI.

GARDNER, L.; BRUNDAGE, J.; BURKE, D.; McNEIL, J.; VISINTINE, R. \& MILLER, R., 1989. Spatial diffusion of the human immunodeficiency virus infection epidemic in the United States, 1985-87. Annals of the Association of American Geographers, 79:25-43. igualmente ser utilizadas para auxiliar na determinação de parâmetros de modelos espaciais de previsão da AIDS. No caso dos modelos espaciais de previsão, em que pode ser importante considerar a influência das vizinhanças, medidas como as autocorrelações espaciais (que variam para cada região) podem ser incorporadas como parâmetros adicionais específicos, aumentando a precisão dos resultados.
LAM, N. S.; FAN, M. \& LIU, K., 1996. Spatial-temporal spread of the AIDS epidemic, 1982-1990: A correlogram analysis of four regions of the United States. Geographical Analysis, 28:93-107.

LOYTONEN, M., 1991. The spatial diffusion of human immunodeficiency virus type 1 in Finland, 19821997. Annals of the Association of American Geographers, 80:127-151.

LOYTONEN, M. \& ARBONA, S., 1996. Forecasting the AIDS epidemic in Puerto Rico. Social Science in Medicine, 42:997-1010.

MARSHALL, R. J., 1991. Mapping disease and mortality rates using empirical Bayes estimators. $A p$ plied Statistics, 40:283-294.

MATHSOFT INCORPORATION, 1997. S-Plus for Windows, Version 4.0. Seattle: Mathsoft Inc.

MS (Ministério da Saúde), 1999. Boletim Epidemiológico-AIDS, 12(3), Semana Epidemiológica, junho/agosto.

ODEN, N., 1995. Adjusting Moran's I for population density. Statistics in Medicine, 26:17-26.

SZWARCWALD, C. L.; BASTOS, F. I.; LOURENÇO, T. A. \& CASTILHO, E. A., 1997. AIDS: O mapa ecológico do Brasil, 1982-1994. In: Epidemia de AIDS no Brasil: Situações e Tendências (P. N. Chequer \& M. G. Medeiros, org.), pp. 27-44, Brasília: Coordenação Nacional de DST e AIDS, Secretaria de Projetos Especiais de Saúde, Ministério da Saúde.

SZWARCWALD, C. L. \& CASTILHO, E. A., 1999. Estimativa do número de pessoas de 15 a 49 anos infectadas pelo HIV, Brasil, 1998: Uma nota técnica. Boletim Epidemiológico - AIDS, 12(2), Semana Epidemiológica, 9 a 21, março/maio.

WALTER, S. D., 1993. Assessing spatial patterns in disease rates. Statistics in Medicine, 12:1885-1894. 